ojs.uv.es/index.php/qdfed

Rebut: 17.05.202I. Acceptat: II.08.202I

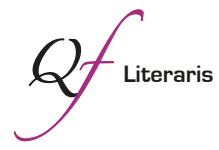

Per a citar aquest article: Feld, Claudia \& Salvi, Valentina. 202I. “¿Qué hacen los perpetradores cuando hablan? Aportes metodológicos a partir de una investigación sobre declaraciones públicas de represores (Argentina, 1976-2018)". Quaderns de Filologia: Estudis Literaris XXVI: I8I-204.

doi: $10.7203 /$ qdfed.26.22107

\title{
¿Qué hacen los perpetradores cuando hablan? Aportes metodológicos a partir de una investigación sobre declaraciones públicas de represores (Argentina, 1976-2018)
}

\author{
What do Perpetrators do when they speak? Methodological Contributions based \\ on a Research about Repressors' Public Statements (Argentina, I976-20I8)
}

\author{
Claudia Feld \\ (CIS-IDES/CONICET) \\ clavife@yahoo.com.ar
}

VALENTina SALVi

(CIS-IDES/CONICET/UNTREF)

valentinasalvi@hotmail.com

\begin{abstract}
Resumen: El estudio de la palabra de los perpetradores de crímenes de masa conlleva desafíos epistemológicos y teóricos específicos. El presente artículo se propone aportar algunas claves conceptuales y metodológicas a partir de la revisión integral de una extensa investigación realizada colectivamente sobre declaraciones de represores de la dictadura argentina que hablaron públicamente entre 1976 у 2018 . Para ello, se abordan tres ejes sustantivos: primero, los procesos sociales de construcción de la figura del perpetrador y su constitución como objeto de estudio para las ciencias sociales; segundo, la palabra de los perpetradores en sus dimensiones representacional, performativa y "veritativa"; y tercero, los marcos temporales en que se encuadran estos discursos, para atender a las maneras en que son socialmente producidos, demandados y escuchados en diversos contextos. El planteo teórico-metodológico aquí desarrollado busca abandonar las perspectivas descriptivas, esencialistas y naturalizantes, y abordar las distintas aristas de un fenómeno que es sociológicamente relacional, históricamente multitemporal y éticamente dilemático.
\end{abstract}

Palabras clave: perpetradores; declaraciones; metodología; dictadura; Argentina.

\begin{abstract}
The analysis of perpetrators' statements implies specific epistemological and theoretical challenges. This article aims to provide some conceptual and methodological keys based on a comprehensive review of an extensive research carried out collectively on the statements of Argentine perpetrators who spoke publicly between 1976 and 2018 . We focus on three substantive aspects: first, how the figure of perpetrator is socially constructed and how it becomes
\end{abstract}


an object of study in social sciences; second, representational, performative and "truthful" dimensions of perpetrators words; and third, the temporal frames of these discourses in order to pay attention to the ways in which they are socially produced, demanded and listened to in various contexts. The theoretical-methodological approach developed here seeks to avoid descriptive, essentialist and naturalizing perspectives, and try to address different aspects of this phenomenon as sociologically relational, historically multitemporal and ethically dilemmatic. Keywords: perpetrators; statements; methodology; dictatorship; Argentina.

\section{Introducción}

En el seminario publicado bajo el título Pensar en términos relacionales, Pierre Bourdieu afirmaba:

la construcción del objeto (...) no es algo que se hace de una vez y para siempre, mediante una suerte de acto teórico inaugural, de antemano; sino que es un trabajo de larga duración, que se realiza de a poco, mediante retoques sucesivos y correcciones, de acciones minúsculas pero decisivas (Bourdieu, 2005: 3I7-318).

Retomando estas consideraciones, en el presente artículo nos interesa revisitar una investigación colectiva recientemente publicada sobre las declaraciones públicas de perpetradores argentinos (Feld \& Salvi, 20I9a ${ }^{\mathrm{I}}$ ), para centrarnos en las características de ese controvertido objeto de estudio y señalar algunas particularidades del abordaje teórico-metodológico que hizo posible su análisis. El presente texto se propone dar cuenta de una mirada integral sobre ese trabajo realizado, con la idea de presentar, ya no las conclusiones de los distintos estudios de caso, sino las herramientas teórico-metodológicas que se fueron delineando a lo largo del trabajo investigativo. Si bien las consideraciones aquí expuestas son el emergente de dicho proceso, la propuesta es que estas nociones y perspectivas permitan indagar fenómenos similares en otros contextos y situaciones históricas. De manera general, sostenemos que estas reflexiones pueden resultar útiles para abandonar perspectivas descriptivas, esencialistas y naturalizantes y abordar las distintas aristas de un

\footnotetext{
${ }^{\mathrm{I}}$ La investigación principal se publicó en un libro que toma io casos de declaraciones de represores, en el que se explica claramente el abordaje y se sintetizan los principales resultados de este trabajo colectivo (Feld \& Salvi, 20I9a; Feld \& Salvi, 20I9b). Asimismo, otros artículos que expanden el abordaje y los objetos han sido publicados en revistas científicas en el marco de este proyecto (Feld \& Salvi, 2020a y 2020b; Feld \& Salvi, 20I6; Diz, 2020; Verzero, 2020; Salvi, 2020).
} 
fenómeno que es sociológicamente relacional, históricamente multitemporal y éticamente dilemático.

En el mencionado proyecto colectivo, un equipo interdisciplinario de diez investigadores e investigadoras estudiamos las declaraciones públicas realizadas por perpetradores argentinos desde los años de la dictadura militar (I976I983) hasta los actuales juicios por crímenes de lesa humanidad (iniciados en 2005 y que hemos estudiado hasta 2018). ${ }^{2}$ Nos ocupamos concretamente de analizar declaraciones producidas en escenarios y ámbitos públicos, como discursos oficiales, audiencias judiciales, entrevistas periodísticas, programas de televisión, libros o autobiografías, cartas o comunicados, entre otros. Más allá de la masividad o no de las audiencias alcanzadas y de los distintos medios utilizados, partimos del supuesto de que -justamente por su carácter público y a diferencia de otros discursos realizados en la intimidad o en ámbitos restringidos- el pronunciamiento y la circulación de estas declaraciones tuvieron destinatarios variados y produjeron efectos, debates, reacciones y repercusiones en diversos escenarios y entre múltiples actores sociales.

La investigación analizó los dichos de distintos militares y policías que actuaron en la represión legal y en la clandestina ejecutada por la dictadura. ${ }^{3}$ Sus declaraciones se estudiaron de manera sincrónica y diacrónica, abarcando un periodo que va desde la dictadura hasta la actualidad ${ }^{4}$. Nos interesó indagar

\footnotetext{
${ }^{2}$ La investigación se realizó en el marco del PICT (2013-0299) "Las declaraciones públicas de represores: narrativas y conflictos en la memoria social sobre el terrorismo de Estado en la Argentina", dirigido por Claudia Feld, con sede en el CIS-CONICET/IDES y financiado por FONCYT, Argentina. El equipo que fue parte activa en esta investigación estuvo conformado por Valentina Salvi, Paula Canelo, Luciana Messina, Enrique Andriotti Romanin, Lorena Verzero, Santiago Garaño, Diego Galante, Eva Muzzopappa y María Luisa Diz.

3 Durante la última dictadura militar (I976-I983), las Fuerzas Armadas en el gobierno impusieron un sistema de represión clandestina basado en la desaparición forzada de miles de hombres y mujeres. Esta metodología represiva incluyó el secuestro, la tortura, el cautiverio en centros de detención, las ejecuciones clandestinas y el ocultamiento de los restos de las personas asesinadas. También hubo una sistemática apropiación de niñas y niños nacidos durante el cautiverio de sus madres. Los organismos de derechos humanos han calculado en treinta mil la cantidad de desaparecidos del periodo; los centros clandestinos de detención emplazados en todo el país se calculan en más de quinientos.

${ }^{4}$ Algunos de los casos estudiados corresponden a represores públicamente conocidos, que ocuparon altos cargos políticos durante la dictadura como los comandantes de las Juntas Militares -Jorge Rafael Videla entre ellos-, Albano Harguindeguy, Horacio Mayorga y Miguel Etchecolatz y de otros con menor notoriedad que fueron parte del aparato represivo como Raúl Vilariño, Julio Simón, Julián Corres, Omar Torres y Eduardo Costanzo. Ademas de estos casos, la investigación reveló los dichos de muchos otros represores que fueron sistematizados en un base de datos que se encuentra en proceso de digitalización y puesta en línea.
} 
en el modo en que las declaraciones de quienes fueron responsables del crimen de desaparición forzada de personas incidieron en las luchas pasadas y presentes por comprender lo sucedido durante la dictadura y también en los procesos políticos posteriores de reparación y justicia. Para atender a la complejidad de este fenómeno, se analizaron las condiciones de posibilidad de estos discursos, sus marcos de interpretación, sus escenarios de ocurrencia, sus contenidos, y especialmente sus impactos, repercusiones, y efectos sociales y políticos a través del tiempo. Este estudio en profundidad nos permitió ver que, a pesar del silencio corporativamente mantenido, de la escasa o nula colaboración de los perpetradores en el esclarecimiento de los hechos, y de que en la mayoría de los casos justificaron o negaron los crímenes cometidos, estas voces constituyen un aspecto controversial, pero no poco significativo, de los procesos sociales de elaboración colectiva del pasado en Argentina. En ese sentido, nuestro trabajo ha colaborado para abrir líneas de análisis que intentan des-esencializar esta palabra para aproximarla a su historicidad (Scott, 200I), es decir, a los modos en que es producida, valorada, demandada y escuchada socialmente en diversos contextos, para comprenderla como un factor activo de los procesos memoriales.

Con algunas excepciones (Arfuch, I995; Feld, 200I, 2009; Payne, 2008), el estudio de la palabra de los perpetradores ha sido tardío y marginal en Argentina. Hasta hace poco, no se habían producido investigaciones sistemáticas ni se había considerado la significativa influencia de las declaraciones de los represores en los procesos de elaboración de memorias sociales sobre el pasado reciente. El abordaje de este tema desde las ciencias sociales se vio dificultado por diversos procesos y fenómenos, que van desde los resquemores y desconfianzas de los actores que luchan por obtener justicia y reparación, hasta las trabas y resistencias de los/as propios/as investigadores/as para repensar ciertas categorías y representaciones asociadas a los perpetradores, sin deslizarse hacia el relativismo o la justificación en lo que hace a las responsabilidades por los crímenes (Feld \& Salvi, 20ı6).

Sin embargo, hace algunos años estos obstáculos pudieron empezar a superarse, posiblemente, en parte, debido al nuevo contexto y los extensos debates que se generaron a partir de los cientos de represores juzgados por crímenes de lesa humanidad desde $2005^{5}$. En ese marco, ciertos trabajos de

\footnotetext{
5 En junio de 2005, la Corte Suprema de la Nación declaró inconstitucionales las leyes de Punto Final (I986) y Obediencia de Debida (I987), que había cancelado la persecución penal a los responsables del terrorismo de Estado, avalando la Ley 25.779 mediante la cual el Congreso
} 
investigación académica comenzaron a enfocarse en la figura de los perpetradores, sus memorias y sus intervenciones en la arena pública (Salvi, 20I2; Ranelletti, 20I8; Salazar, 20I7; Martin, 20I7; Hilb, 20I4). ${ }^{6}$ Más allá de los condicionamientos propios de este escenario nacional, el interés que adquirió esta problemática, no debe comprenderse, en términos generales, de manera simplista como la respuesta a un área de vacancia preexistente que la investigación social habría venido a llenar como resultado de su avance natural, sino como parte de ciertos debates en curso en los que esta se insertó y buscó intervenir.

Estos debates sociales sobre la actuación de los represores, las formas en que fueron socialmente representados y las estrategias de las víctimas para denunciarlos y visibilizarlos ${ }^{7}$, constituyeron sin duda el sustrato que (in)formó y dio forma a nuestra investigación, pues esta encontró, en ese entorno social y político, sus condiciones de posibilidad. Sin embargo, no hay que perder de vista que abordar analíticamente este fenómeno requirió discutir y criticar ciertos sentidos asentados en el campo interdisciplinario de investigaciones sobre memorias sociales e historia reciente. La investigación, por lo tanto, se inscribe tanto histórica y políticamente en su contexto de emergencia, como teórica y metodológicamente en el campo de investigaciones en el cual se realiza. Ya que en otros trabajos hemos abordado extensamente el primer aspecto (Feld \& Salvi, 20I6; 20I9a y b; 2020), en este caso intentaremos pensar el segundo y discutir algunos de los desafíos específicos, tensiones y problemas

había anulado dichas normas de impunidad en 2003. De este modo, quedó allanado el camino para que avanzasen los juicios por delitos de lesa humanidad. Hasta marzo de 202I, el total de causas por delitos de lesa humanidad son 626. El total de personas investigadas asciende a 3490 , de los cuales I025 fueron condenadas, 7I5 han fallecido, entre procesados e imputados hay I24I y I65 fueron absueltos, entre otras figuras. https://www.fiscales.gob.ar/lesa-humanidad /a-45-anos-del-golpe-de-estado-suman-I025-las-personas-condenadas-por-crimenes-de-lesahumanidad-en-254-sentencias/ [Acceso 6/05/202I].

${ }^{6}$ Incluso en los últimos años se produjo en Europa un desarrollo investigativo que recibió el nombre de "giro perpetrador" que, a diferencia de los estudios que estamos mencionando, se ha enfocado en los tratamientos literarios y culturales que han tenido estas figuras (Ferrer \& Biosca, 2019).

7 En Argentina, dar cuenta de la verdadera identidad de los represores, que casi siempre se identificaban por alias en las acciones de represión clandestina, fue una tarea tempranamente emprendida por los sobrevivientes y las organizaciones de derechos humanos. La confección de listas con nombre, apellido y apodo, la construcción de los organigramas de las cadenas de mandos, la identificación de los miembros de las "patotas" que operaban en cada CCD en base a testimonios de sobrevivientes permitió la creación de un acumulado de información sobre la identidad de los represores que sirvió como insumo para las tareas de la CONADEP y la posterior acción judicial. 
que este objeto de estudio plantea en el marco de nuestro campo de trabajo e investigación ${ }^{8}$.

El presente artículo se propone profundizar en estas aristas en torno a tres dimensiones. En primer lugar, nos interrogaremos sobre los procesos sociales de construcción de la figura del perpetrador y de qué maneras, bajo ciertas condiciones heurísticas, se puede transformar en objeto de estudio para las ciencias sociales. En segundo lugar, nos centraremos en la palabra de los perpetradores, tanto en su dimensión representacional -esto es, el contenido de sus dichos y los modos de significar el pasado de violencia-, como en la performativa, pues además de evocar o recordar el pasado, sus dichos inciden en la realidad en la que tienen lugar. En este aspecto, además, problematizaremos la dimensión "veritativa" (Ricoeur, I999) de esa palabra dicha públicamente y las expectativas de que "la verdad sea dicha" que rodea a estos discursos. Finalmente, reflexionaremos sobre los marcos temporales u "oleadas" en que se encuadra la palabra pública de los perpetradores, a lo largo del periodo estudiado, en función de sus condiciones de posibilidad, sus impactos y repercusiones, que no pueden ser separados de sus condiciones de escucha y de las mediaciones sociales e institucionales con las que se interpretan en distintas coyunturas.

\section{La figura del perpetrador}

La comprensión de la figura del perpetrador en las sociedades posdictatoriales encierra una paradoja que hace a su constitución como objeto de estudio. La demostración factual de las acciones criminales cometidas en el pasado, ya sea por la prueba jurídica o por la reconstrucción historiográfica, no alcanza para dar cuenta, por sí sola, del complejo proceso de construcción de esta figura. El crimen a gran escala, las ominosas condiciones en que fue cometido y la acción deliberada y sistemática de ocultamiento y negación, sin duda, inscriben la agencia del perpetrador en un proceso histórico de violencia política. Todos estos elementos constituyen razones necesarias, aunque no suficientes, para delimitar esta categoría social.

En ese sentido, la demostración judicial y la comprensión histórica del carácter criminal de las acciones cometidas constituyen mediaciones -una

\footnotetext{
${ }^{8}$ Agradecemos especialmente a Jaume Peris Blanes por sus generosas precisiones sobre aspectos metodológicos de nuestra investigación, expresadas en diferentes seminarios y espacios de intercambio académico.
} 
institucional y la otra científica- imprescindibles para hacer frente a las posturas negacionistas de los hechos y de las responsabilidades. No obstante, son insuficientes para comprender el lugar social que ocupan los perpetradores en las diversas sociedades. Además, las nociones de "criminal de masa", "perpetrador" o "genocida", construidas por las víctimas al calor de las luchas por la justicia y la memoria, son muy diferentes a las que los propios agentes de la represión utilizan para dar cuenta de su experiencia y creencias en contextos de violencia. En Argentina, por muchos años, los miembros de las Fuerzas Armadas y de Seguridad, signados como responsables del terrorismo de Estado, se identificaron a sí mismos como "salvadores de la patria" o "vencedores de la guerra antisubversiva", y a través de la figura de los "combatientes" reivindicaron su accionar criminal presentándolo como actos de servicio contra el enemigo de la nación (Salvi, 20I2).

En este marco, la investigación que realizamos tuvo que construirse dando forma a dos problemas, que si bien fueron puntos de partida necesarios para delinear el objeto, debieron ser reformulados y complejizados a medida que avanzaba la pesquisa. El primero surgió de interrogarnos sobre cómo definir los contornos del objeto a observar, esto es, los responsables de los crímenes dictatoriales en un sentido amplio. El segundo consistió en preguntarnos qué categoría era la más apropiada para nombrarlo.

El primer dilema se pregunta a quiénes investigar, es decir, qué sujetos eran aquellos cuya palabra pública era objeto de nuestro estudio. La demarcación de ese universo de personas, como ya dijimos, no va de suyo, y nunca es "natural" ni "objetiva”, no se define fáctica o jurídicamente, ni es una categoría nativa de los propios protagonistas. Cuando dimos los primeros pasos en nuestra investigación, recortamos el universo de perpetradores que iba a ser nuestro objeto de observación entre aquellos que eran probadamente responsables del crimen de desaparición forzada de personas. Los juicios en curso y los desarrollos historiográficos nos permitían seleccionar un grupo amplio de militares, policías y civiles que habían actuado en el terrorismo de Estado. Sin embargo, este criterio resultaba una limitante, pues invisibilizaba a aquellos otros que estaban en un estatus más ambiguo, como quienes fueron señalados o denunciados por las víctimas aunque sus procesamientos judiciales todavía estaban en curso, o aquellos que ni siquiera habían sido imputados, o los que habían fallecido antes de los juicios. Por otra parte, esta categorización se volvía anacrónica a la hora de ir hacia atrás en el tiempo cuando buscábamos hacer foco en los dichos de perpetradores que, con anterioridad a los procesos judiciales actuales, ostentaban una cara pública que no los calificaba como "represores". 
Ante estas limitaciones buscamos ampliar el universo de observación. Pero no se trató de aumentar la variedad de individuos que componen un conjunto delimitado previamente, sino de identificar y analizar cuáles fueron las maneras en que social e históricamente se fue configurando ese conjunto que mostró bordes difusos y sentidos inestables. De allí que hicimos foco en diversas coyunturas, identificamos voces de actores señalados, denunciados o sospechados de participación en el terrorismo de Estado, incluso estudiamos figuras liminares cuya participación es aún hoy terreno de disputa. Lo hicimos con el propósito de analizar cómo sus dichos eran socialmente interpretados y recibidos, contestados y desmentidos por diversas audiencias. De este modo, surgieron voces, actores y trayectorias disímiles entre sí. Entre ellos, se contaban figuras públicas con poder y autoridad dentro del régimen militar como el ministro de Interior de la dictadura, Albano Harguindeguy, quién operó como el "agente legal más involucrado en los crímenes de los agentes ilegales" (Canelo, 2019: 80); o figuras con cierto reconocimiento social, como el contraalmirante Horacio Mayorga, quien fue el espadachín moral de la Armada, encargado de limpiar su cara pública hacia fuera y evitar fisuras en el "pacto de silencio" hacia dentro de sus filas (Muzzopappa, 20I9). También consideramos casos más difusos, de personas cuyas responsabilidades individuales resultaron difíciles de precisar en términos penales como fue el gendarme Omar Torres, quien además de haber cumplido tareas de guardia exterior de dos centros clandestinos de detención, muy tempranamente prestó testimonio y dio información valiosa ante distintas instancias estatales y judiciales (Garaño, 20I9). Por último, el trabajo implicó también incorporar un tipo de acción criminal particular del caso argentino, como fueron las personas que se apropiaron y falsearon la identidad de niños/as secuestrados/as con sus padres o nacidos/as durante el cautiverio de sus madres (Diz, 2020). ${ }^{9}$

En definitiva, evitamos ceñirnos a un universo cerrado y, por tanto, estabilizado de agentes de la represión, y procuramos observar cómo en diversos escenarios y contextos de enunciación, ese universo se fue angostando, en-

\footnotetext{
9 La mirada sobre la apropiación de niños/as nos permitió observar no solo una nueva categoría (la de los "apropiadores" / "apropiadoras"), también nos permitió complejizar la dimensión de género, ya que muchos de estos casos mostraban las relaciones entre varones y mujeres (Diz, 2020). En términos generales, la categoría "represor" remite al género masculino, pues en su inmensa mayoría los miembros del aparato represivo fueron hombres. Unas pocas mujeres fueron miembros del servicio penitenciario, policías o civiles involucradas en el sistema represivo, y algunas de ellas afrontaron cargos en los juicios por crímenes de lesa humanidad (Mariani, 20I8).
} 
sanchando y/o complejizando a partir del examen de los debates, impactos y repercusiones que las declaraciones públicas provocaron en varios círculos sociales. Estos discursos resultaron importantes no solo por lo que decían, sino por la caracterización y visibilización que hicieron sobre quienes los pronunciaban. En fin, prestar atención a estas voces, pero sobre todo a los procesos de circulación, recepción y escucha nos permitió entender que la categoría social "perpetrador" es en sí misma relacional, pues se construye en su espejo social, involucrando en su proceso de constitución a un conjunto de actores, saberes, discursos e instituciones en disputa y en tensión por la asignación de sentidos en los contextos posdictatoriales o posviolencia.

El segundo dilema tuvo que ver con el modo de denominar a los perpetradores, es decir, con la categoría que debía utilizarse para nominar este universo que resultó, como ya mostramos, no solo heterogéneo sino también inestable en el tiempo. El carácter socialmente contingente de la categoría "perpetrador" y de los sistemas de clasificación que le dan forma resultó un desafío epistemológico para nuestra tarea de investigación. Por eso, hicimos foco en dos estrategias analíticas para comprender cómo se delimitaban las taxonomías y nociones sociales que dan forma a esa categoría: la histórica y la simbólica.

A través de la vía histórica buscamos analizar el reportorio de categorías socialmente disponibles, identificar su contexto de surgimiento y sus capas de sentido, en suma, preguntarnos por la historicidad de términos muy presentes en la arena pública argentina como "torturador", "represor" o "genocida”. En consecuencia, la investigación fue mostrando que, en Argentina, la definición de las categorías para referirse a los militares y la comprensión de sus responsabilidades se produjeron de manera paulatina y no sin tensiones y contramarchas. En el primer año de la transición, la noción de "represor" io si bien no estaba completamente ausente, no constituía una categoría colectiva o englobante para designar al conjunto de los responsables de un mismo tipo

${ }^{10}$ La noción de represor tiene en Argentina un sentido inequívoco, a diferencia de la de perpetrador, pues refiere de manera exclusiva a los miembros de las fuerzas represivas sean las FF. AA. y de Seguridad y Personal Civil de Inteligencia que participaron en el terrorismo de Estado y, por tanto, no resulta factible de ser aplicada a los miembros de las organizaciones armadas de izquierda. En el marco de la Comisión de Verdad y Reconciliación de Sudáfrica la categoría "perpetrador" engloba indistintamente a todos los que cometieron crímenes ya sean integrantes de las fuerzas de seguridad del sistema del Apartheid o sus opositores (Salvi, 20I6). Si bien es una categoría que remite al género masculino pues en su mayoría los miembros del aparato represivo fueron hombres, también hubo mujeres que fueron miembros del servicio penitenciario y de las policías, y que participaron en la represión como apropiadoras de niños. 
de crimen: la desaparición (Feld \& Franco, 2015; Salvi, 20I9). En esos años, los miembros de las juntas militares que habían encabezado la dictadura eran tratados por la prensa como funcionarios del régimen anterior y como oficiales superiores de las Fuerzas Armadas (FF. AA.). Solo algunos militares que se caracterizaban por vanagloriarse públicamente por la violencia eran señalados como responsables, pero en términos individuales (Feld, 20I9a). Fue recién a mediados de los noventa, a más de una década de terminada la dictadura, cuando la categoría "represor" se estabilizó y adquirió los sentidos que tiene hoy, especialmente a partir de los llamados escraches promovidos por la organización HIJOS ". Más tarde, ya iniciado el siglo xxi, las figuras "represor" o "genocida" se volvieron socialmente extendidas, tras la celebración de los primeros juicios por crímenes de lesa humanidad. Nuestra investigación nos permitió observar que, cuando hablamos de "represor", de "genocida" o de "torturador", estas categorías cargan no solo con las marcas de los procesos políticos y las luchas memoriales con las que diversos actores buscaron denunciar y hacer visibles los crímenes en variados contextos y con resultados disímiles, sino también con los sentidos y significaciones con los que la sociedad de la posdictadura los imaginó y representó. En suma, las categorías son el efecto de estas luchas por la representación del pasado en distintos contextos y en medio de disputas sociales por la memoria.

La vía simbólica, por su parte, nos posibilitó entender que, como parte de los debates memoriales, los usos sociales de la figura del perpetrador influyeron en la configuración, tal como sostiene Giesen (200I: I9), de la separación entre el bien y el mal en las sociedades posviolencia. Esto conlleva la sedimentación en figuras más o menos estereotipadas que han tenido, por ejemplo en Argentina, alta circulación pública como la figura de los "monstruos" -que deposita en cada represor una inmanente maldad personal-, la de los "cruzados" -que sostiene la idea de un fanatismo ciego, la del demente -que insiste en el carácter perverso de los actos-, o incluso, la del burócrata-que subsume la agencia de cada individuo en la maquinaria criminal.

Ante esta problemática, la investigación requirió del desacople entre las categorías conceptuales y las nativas para problematizar esas significaciones fuertes que crecieron al calor de las luchas por la memoria y la justicia. Pero

\footnotetext{
II Cuando estaba cancelada la posibilidad de persecución penal, los escraches fueron un novedoso instrumento de acción política que buscaba someter a los represores a la condena social a través de la visibilización de su identidad, su trayectoria criminal y su lugar de residencia. Para trabajos de investigación sobre escraches (ver, entre otros, Da Silva Catela, 200I: 262).
} 
también buscó entender que los sistemas de clasificación con los que se define la naturaleza de los hechos cometidos, o los valores morales con los que se caracteriza la subjetividad y la agencia de los perpetradores son el resultado de procesos sociales, políticos y culturales que se realizan, no sin tensiones y debates, al interior de cada sociedad y con una dinámica que asume diversas fisonomías a lo largo del tiempo. Incluso, se concentró en identificar que los propios perpetradores también tienen una participación activa y capacidad de incidencia, ya sea reivindicando el carácter heroico y patriótico de sus actos, como negando la existencia de los hechos criminales denunciados por las víctimas, descalificando y maltratando públicamente a sus denunciantes, o desmereciendo las acusaciones por su supuesto "carácter político".

En suma, la investigación comprobó que el estudio de las declaraciones públicas de represores constituye, pues, una puerta de acceso privilegiada a esta problemática, lo que permite complejizar estereotipos, identificar capas genealógicas de sentido y ayudar, así, a comprender más cabalmente el tipo de figuras que se elaboran a lo largo del tiempo, de maneras diversas, en el marco de determinadas relaciones de fuerza. Lejos de partir de un concepto y de un universo dado, cada proceso político posviolencia aporta las claves históricamente situadas para comprender y complejizar las nociones de perpetrador que serán objeto de investigación.

\section{Las declaraciones públicas de los perpetradores}

El carácter público de la palabra de los perpetradores le otorgó al objeto de estudio un matiz epistemológico distintivo, pues se trata de una palabra que fue producida y emitida, directa o indirectamente, para su circulación en el espacio público, y no producto de intercambios privados o de entrevistas realizadas con fines de investigación.

El análisis diacrónico llevado adelante en nuestra investigación nos permitió descubrir que las particulares condiciones de enunciación y de escucha que se modifican a lo largo del tiempo redundaron en una forma específica de presencia de su palabra en la vida pública. Por otra parte, el examen sincrónico de cada uno de los escenarios con sus diferencias específicas produjo formas particulares de valorización de la palabra de los perpetradores. No es igual la lógica espectacular y exhibitiva que suelen producir los medios masivos de comunicación, sus estrategias para tematizar y presentar los dichos, que las mediaciones, requerimientos y respuestas que impone el funcionamiento de las instancias judiciales. 
Ahora bien, ¿cómo examinar esos discursos? ¿Qué dimensiones se volvieron significativas en el análisis? Al menos tres dimensiones fueron fundamentales para entender los contenidos de esos dichos y sus incidencias en la trama social. El problema no fue solo "qué dijeron" sino también "qué hicieron" cuando hablaron y qué se esperaba que esos dichos produjeran. Expondremos muy brevemente las tres dimensiones trabajadas en nuestra investigación: la representacional, la performativa y el problema de la verdad. Si bien todas ellas operan de manera articulada, su distinción analítica permite comprender más cabalmente los vínculos y tensiones entre los actos del pasado y los discursos del presente, entre lo dicho y lo interpretado, entre la representación y la acción. Estos tres ejes nos permiten interrogar tanto los discursos en sí de los perpetradores como los impactos, efectos y repercusiones que tuvieron en determinados contextos de enunciación y escucha.

\subsection{Dimensión representacional}

Esta dimensión nos permitió acercarnos a un tema esquivo de entender, como es el de la agencia y la cosmovisión de los responsables de los crímenes dictatoriales. Al analizar los modos en que los perpetradores cuentan la historia y se posicionan frente a ella, pudimos comprender los sentidos, representaciones y valores evocados y actualizados en los dichos de los represores a lo largo de tiempo.

Entre esas claves narrativas que estructuran los discursos de los perpetradores, vimos que estaban muy presentes aquellas construidas por la propia dictadura -o incluso, antes, por las instituciones armadas- para justificar o reivindicar las acciones criminales. En este sentido, tuvieron gran circulación entre los miembros de las Fuerzas Armadas y de Seguridad de Argentina los discursos en clave de "guerra antisubversiva", de "obediencia" y de "excesos".

El discurso de la "guerra antisubversiva" es el núcleo duro de la cosmovisión militar en términos amplios y considera al accionar de las FF. AA. como la respuesta de las "fuerzas del orden" a la ofensiva emprendida por las organizaciones armadas durante los años sesenta y setenta. Según este discurso, las FF. AA. participaron en una "guerra no convencional" en la que la metodología fue impuesta por un enemigo definido como terrorista que operaba en la clandestinidad. Como parte sustantiva del ethos militar, la noción de "obediencia debida" sostiene que las acciones realizadas por las FF. AA. fueron "actos de servicio" en el marco de órdenes legítimas emanados de los superio- 
res (Galante, 20I9). Por último, la figura de los "excesos", que surgió durante los años de la dictadura como discurso exculpatorio, niega la sistematicidad de la represión y la reduce a casos excepcionales cometidos por los cuadros medios y bajos supuestamente "fuera de control".

En las declaraciones públicas estudiadas, estas narrativas se repiten en numerosas ocasiones. Sin embargo, estos discursos portan también otras claves que tensionan esas nociones más cristalizadas. Una de ellas es la temática del "honor", que aunque es típica del discurso militar, en este nuevo marco cobra otra dimensión, ya que intenta darle un valor moral positivo a los crímenes aberrantes de la dictadura (Muzzopappa, 20I9). Otras claves narrativas utilizadas en los discursos más recientes de los perpetradores, provienen, en realidad, del universo de las víctimas. Los agentes de la represión hacen uso del lenguaje y los valores de las organizaciones humanitarias que han denunciado esos crímenes y a sus responsables, para presentarse ellos mismos como "víctimas" de la acción de la justicia, "víctimas de la subversión" o, incluso, "víctimas de una memoria parcial". Cuando se las observa a lo largo del tiempo, vemos que algunas claves narrativas tuvieron gran estabilidad y mantuvieron posiciones de reivindicación o justificación de lo actuado. Sin embargo, otras fueron cambiando en función de los contextos, en los que estos militares fueron mostrando estrategias novedosas para responder a la dinámica de los debates sobre el pasado.

Por su parte, el análisis de las declaraciones en función de las trayectorias de los represores ha permitido identificar cómo han influido los capitales simbólicos y culturales de los que disponen y sus posiciones dentro de la escala de mando y en el marco de las operaciones represivas clandestinas en lo que dijeron públicamente, así como en sus formas discursivas y de argumentación, según se trate de cuadros bajos, medios o altos del aparato represivo. En sus alocuciones públicas, los más altos mandos, los jefes militares con responsabilidades políticas y criminales en la planificación y ejecución del terrorismo de Estado en Argentina, se han dirigido hacia distintas audiencias en función de las coyunturas que se sucedieron a lo largo de cuatro décadas. Por eso, es importante distinguir entre los diversos destinatarios: por una parte, los cuadros militares -ya sean subordinados, camaradas de armas o nuevas generaciones de militares- $y$, por otra parte, audiencias más amplias como la dirigencia política, la sociedad en su conjunto o, incluso, la historia. Cuando se han dirigido a las filas militares, estos altos mandos han destacado su lugar como miembros de una institución con valores excepcionales como el sacrificio, la obediencia, el coraje. Este recurso les ha permitido tomar la palabra 
públicamente como "oficiales respetables" entre sus pares y al mismo tiempo como miembros de una institución "honorable" para mantener la cohesión corporativa en los miembros de las Fuerzas Armadas frente a las acusaciones sociales (Galante, 20I9). Cuando se dirigieron a la sociedad civil en su conjunto, si bien mayormente continuaron ocultando aspectos sustantivos de los hechos, desarrollaron distintos recursos para nombrar a medias lo que resulta innombrable: el crimen de la desaparición de personas (Canelo, 2019).

\subsection{Dimensión performativa}

Las declaraciones de perpetradores constituyen también "actos de habla", en los que el lenguaje verbal tiene la capacidad de incidir en la realidad en la que se instala (Austin, 1996). En ese aspecto, se nos planteó la cuestión de cómo analizar ciertos discursos de perpetradores que, en sus contextos de producción iniciales, habían sido interpretados como "actos de habla". Sobre todo, el dilema era cómo considerarlos si esas acciones, a nuestro entender, no se habían cumplido acabadamente. Un ejemplo fue el caso del supuesto "arrepentimiento" del represor Adolfo Scilingo. En I995, las declaraciones mediáticas de Scilingo sobre los "vuelos de la muerte" y su descripción en primera persona de esos operativos de asesinato fueron interpretadas, en diversos escenarios y por distintos actores, como un "arrepentimiento". La "confesión" y el "arrepentimiento" fueron nociones centrales para interpretar una buena parte de las declaraciones de perpetradores realizadas en los años noventa, mayormente en escenarios mediáticos. Sin embargo, un estudio pormenorizado de esas declaraciones nos permitió ver que ni Scilingo ni muchos otros represores calificados como "arrepentidos" en aquel momento habían cumplimentado esa acción performativa (Feld, 2009). En ese marco, más que desmentir las interpretaciones circulantes o demostrar qué hicieron o dejaron de hacer los perpetradores cuando hablaban, nuestra investigación se propuso relevar las tensiones presentes en esos discursos y hacer jugar esas palabras dichas con los contextos de producción y recepción, con las expectativas de escucha, así como con la red de relaciones sociales involucradas en su impacto, amplificación e interpretación.

En ese marco, detectamos tres tipos de tensiones presentes en las declaraciones que analizamos y vinculadas a los "actos de habla". Un primer grupo de declaraciones se ubicaba en la tensión entre hablar y silenciar, y nos permitió, en nuestro análisis, complejizar la noción del sentido común de "pacto de 
silencio" y el acto que le resultaba complementario, el de "romper el silencio". Nuestra investigación pudo mostrar que la idea de que los represores han guardado silencio sistemáticamente sobre las desapariciones y el terrorismo de Estado no tiene un correlato en la realidad, ya que se han producido todo tipo de declaraciones a lo largo de más de cuarenta años (Feld \& Salvi, 20I9a).

Un segundo grupo de acciones realizadas por las declaraciones públicas de represores tensionan la noción de secreto y su contracara, la revelación. Si bien es cierto que, en muchos casos, los perpetradores conocen informaciones fundamentales para reconstruir crímenes que se han definido por la ocultación de la violencia y de sus pruebas materiales, ese sentido común supone que, cada vez que los perpetradores hablen, revelarán alguno de estos secretos. Sin embargo, la mayoría de las veces, el contenido de lo que dijeron frustró esa expectativa. A través de nuestra investigación, pudimos observar que, aun cuando aportaron información verdadera, en la mayor parte de los casos los represores no dieron nuevas informaciones, sino que enunciaron las que ya eran públicamente conocidas y constituían una verdad socialmente aceptada, incluso a veces probada. Por ejemplo, cuando el exdictador Videla mencionó a los desaparecidos en 20I2, a casi treinta años de terminada la dictadura, expuso cuestiones de público conocimiento y que habían sido probadas en la justicia, tales como que hubo desaparecidos arrojados al Río de la Plata y al Océano Atlántico (Salvi, 20I9a). Al mismo tiempo, algunos militares, como por ejemplo Harguindeguy y Mayorga, pusieron en juego diversas estrategias para seguir ocultando las informaciones desconocidas. O, en otras palabras, para seguir hablando (eludiendo, encubriendo, silenciando) sin revelar lo que todavía se desconoce del terrorismo de Estado.

Un tercer grupo de actos de habla se basa en el hecho de que la palabra pública de los perpetradores puede tener la ignominiosa capacidad de perpetuar el crimen o morigerarlo y, por lo tanto, tiene efectos en el conjunto de relaciones sociales que ese crimen estableció. Estos actos de habla están atravesados por la tensión entre el pasado de la acción violenta y el presente de la declaración. Una de las expectativas sociales que generan las palabras de los represores es que se produzca algún tipo de desacople entre lo que el represor hizo en el pasado -secuestrar, torturar, asesinar, mandar a matar, etcétera-y lo que él mismo puede hacer en el presente -hablar de lo que sabe, reconocer su carácter criminal, entre otras acciones. Es en el marco de esas expectativas que han tenido gran repercusión y circulación social las mencionadas nociones de "confesión" y "arrepentimiento". Pero algunos actos de habla se basaron en la fuerza contraria, ya que muchos de los represores estudiados se identificaron 
con la acción violenta del pasado, ya sea jactándose, reivindicándola, dándole un carácter heroico o justificándola (Feld, 20Igb \& Messina, 2019).

Al hacer declaraciones públicas, los represores producen y reactualizan relaciones sociales. De allí que la performatividad sea un aspecto central de estas declaraciones, pues tiene la capacidad para producir (o reproducir) relaciones entre comandantes y comandados, entre víctimas y victimarios, entre militares y sociedad, y entre pasado y presente.

\subsection{El problema de la verdad}

La compleja relación, históricamente construida, entre la demanda de verdad frente al silencio mantenido por las fuerzas armadas y la expectativa social respecto de lo que los responsables puedan llegar a decir ha sido una dimensión central en nuestro objeto de estudio. Se trata de un problema permanente y repetido en los diversos contextos y declaraciones que estudiamos, y comprenderlo implicó complejizar la noción de verdad sin perder vista la espesura ética que esta cuestión representa para la investigación.

Es cierto que los perpetradores cuentan con información fáctica fundamental para reconstruir los crímenes y que sistemáticamente la han ocultado. También es cierto que, en Argentina, la expectativa social de que "digan lo que saben” ha buscado permanentemente interpelarlos y, al mismo tiempo, denunciar el silencio que guardan. La necesidad de estudiar esta expectativa se presentó como un emergente de investigación pues era parte de una demanda social que asumía la forma de una pregunta: ¿cómo se vincularon los dichos públicos de los perpetradores con la demanda histórica de "saber la verdad" sobre lo sucedido con los desaparecidos? O ¿cómo efectivamente estas voces de represores contribuyeron (o no) al esclarecimiento de la verdad? Nuestra investigación debió desarmar y revisar críticamente las nociones de verdad que subyacen tras estas preguntas a la luz de los estudios de casos en distintos momentos a lo largo de cuarenta años. Para ello, indagamos en dos ejes: primero, los sentidos sociales que fue adquiriendo la categoría "verdad" en los procesos memoriales y las luchas políticas; y segundo, los diferentes planos de enunciación de la verdad sobre el pasado en los que las declaraciones de los represores se inscribieron y, a través de los cuales, contribuyeron a la construcción de sentidos sobre lo sucedido.

Respecto de los sentidos sociales de la noción de "verdad", en Argentina, donde se implementó un plan sistemático de desaparición forzada de perso- 
nas, el pedido de información hacia los responsables ha sido una demanda tempranamente instalada, que asumió la forma de una consigna. ${ }^{\mathrm{I2}} \mathrm{El}$ pedido de "verdad", además de denunciar públicamente el silencio corporativo mantenido por los militares ${ }^{13}$, ha constituido una práctica activa de construcción llevada adelante por diversos actores, especialmente las organizaciones de derechos humanos y algunas instituciones públicas (Jelin, 20I7). Se trató de una inmensa tarea que incluyó, entre muchas otras acciones, la recopilación de testimonios de sobrevivientes y familiares de desaparecidos, la desclasificación y creación de archivos, la identificación de cuerpos NN y la búsqueda y recuperación de niños y niñas apropiados.

Ahora bien, la demanda de "verdad" no se reduce al sentido estrictamente literal de las formulaciones fácticas, esto es, a esa información imprescindible que, como hemos señalado, solo poseen los represores y no ha podido ser averiguada por otros medios. Nuestra investigación mostró que, además del reclamo de esa información, la expectativa de verdad involucró también una demanda ética de que los perpetradores reconocieran el carácter horroroso de los hechos que habían cometido. En ese sentido, la demanda de verdad excede sus especificaciones factuales, aunque no podría elaborarse sin ellas (Oberti y Pittaluga, 20I6: II).

A lo largo de la investigación, identificamos que dicha expectativa se apoyó en un sentido común muy arraigado que daba por sentado que la palabra de los represores tenía una relación inmanente con la verdad. Para muchos de los que, en su momento, recibieron esas declaraciones (periodistas, organismos de derechos humanos, intelectuales, entre otros) la verdad que provendría del discurso de los perpetradores se concebía como "más verdadera" de la que las propias víctimas podían enunciar. Para esos actores, los represores

\footnotetext{
${ }^{12}$ Las consignas "Memoria, Verdad y Justicia" componen la tríada que sintetiza las acciones emprendidas por los organismos de derechos humanos desde los tiempos de la dictadura hasta la actualidad.

${ }^{13}$ Se usa comúnmente la expresión "pacto de silencio" para dar cuenta de la escasa colaboración de los miembros de las Fuerzas Armadas y de Seguridad con información valiosa para el esclarecimiento de lo sucedido durante el terrorismo de Estado. En general, el "pacto de silencio" es representado como una consecuencia o una suerte de epifenómeno de otro pacto, el de sangre, esto es, la participación extensa y rotativa de la mayor cantidad posible de cuadros en trabajos represivos para ensuciar sus manos. Sin desatender el peso que la asociación criminal tiene en el mantenimiento del secreto, es necesario historizar esta suerte de unidimensionalidad explicativa para dar cuenta del carácter relacional y dinámico del límite que demarca lo que los represores dijeron y lo que callaron (Salvi, 2015: 187).
} 
"poseían" y "guardaban" una verdad por el hecho de haber "estado allí" (Feld \& Salvi, 20I9a).

Con el propósito de desarmar este supuesto, durante la investigación avanzamos sobre el segundo eje antes mencionado, dotar de historicidad a la relación entre la palabra de los perpetradores y el problema de la verdad: diferenciar los planos de enunciación de la verdad sobre el pasado en los que las declaraciones de los represores se inscriben y a través de los cuales adquieren significación social. En lugar de presuponer una relación con la verdad como una condición natural derivada de la posición de victimario, analizamos los efectos de esta palabra en el plano de la construcción social de la verdad, en los diversos contextos de enunciación y escucha en los que tuvieron lugar.

De esa manera, la deriva que puede tener la revelación de informaciones socialmente desconocidas cuando se expone públicamente depende directamente de las diversas mediaciones sociales e institucionales de las que dispone una sociedad, en un momento dado, para que sea reconocida y viabilizada como un aporte esclarecedor sobre lo sucedido en el pasado. Por ejemplo, en nuestra investigación vimos que, cuando los perpetradores hablaron en los medios de comunicación, los modos exhibicionistas y el lenguaje sensacionalista colaboraba con la circulación de un discurso hiriente que negaba los hechos sucedidos sin otra mediación que los marcos de lectura de la prensa o la televisión (Feld, 2016). Estos marcos no proveían herramientas para elaborar, por sí solos, una verdad social que rechazara la violencia producida y permitiera comprender, en términos globales, los alcances éticos y políticos del terrorismo de Estado. En cambio, cuando la información brindada por los represores, en las pocas ocasiones en que dieron informaciones valiosas y/o nuevas, circuló por instituciones -como el poder judicial o las comisiones de verdad que cuentan con dispositivos para sopesarla, investigarla, chequearla y encausarla- aportó y contribuyó a la construcción de la verdad social (Feld \& Salvi, 2020).

En definitiva, la investigación histórica mostró que ni la verdad fáctica ni la verdad social sobre los crímenes masivos cometidos por la dictadura se construyen con informaciones sueltas. Cualquier información, provenga de quien provenga, debe corroborarse, cruzarse y acoplarse a la información ya reconstruida por otros actores y sectores. En ese sentido, las declaraciones de los perpetradores, en los escasísimos casos en que han brindado información, muestran que no se trata de dar como existente y/o necesaria una verdad que ellos esconden. Se trata, en cambio, de entender cómo se articula la información que puedan llegar a brindar con un proceso más perdurable y profundo 
que será veraz siempre y cuando se acople al conjunto de verdades ya probadas, que tienen la cualidad de apoyarse unas con otras -en las que la instancia judicial juega un rol fundamental-, y así confluir en una verdad social.

\section{Las temporalidades de la palabra pública de los perpetradores}

El momento histórico es sin duda un factor activo que configura marcos de sentidos en pugna y en construcción por parte de distintos actores, proscribe o prescribe lenguajes y produce significaciones sobre el pasado más o menos estabilizadas. En cada contexto, se perfilan las fronteras de lo decible y escuchable respecto de los discursos de los perpetradores. La alternancia entre el despliegue en la escena pública y el repliegue de estas voces hacia espacios más restringidos dibujaron, a lo largo del tiempo, distintas etapas a las que denominamos "oleadas", que no solo se caracterizaron por la irrupción de las declaraciones de represores en la vida pública, sino también por su amplificación en debates sociales y políticos.

La metáfora de las "oleadas" nos permitió, en primer lugar, entender la convergencia temporal de las diversas declaraciones, que -aun cuando eran palabras individuales, con personajes de trayectoria singular- pudieron entenderse también por su contemporaneidad (volveremos sobre este punto). En segundo lugar, nos posibilitó comprender cierta cualidad ondulatoria, esto es, el movimiento pendular de esta profusión y circulación de declaraciones. Pudimos observar la relación entre los "picos" y los "valles", o -como los hemos llamado- los momentos de despliegue y de repliegue de estas voces en el espacio público. Finalmente, la metáfora de las oleadas nos llevó a prestar atención hacia las repercusiones, efectos y consecuencias de estas declaraciones, que no han sido siempre directas, del estilo causa-efecto, sino que se produjeron a veces como efectos mediados o mediatos, en diversos escenarios, ante diversos actores y en diferentes momentos, a veces muy alejados de la instancia de producción original.

En Argentina, entre I983 y la actualidad, identificamos cuatro "oleadas" con características específicas ${ }^{\mathrm{I} 4}$. Esta mirada en clave histórica nos permitió

\footnotetext{
${ }^{14}$ El libro que hemos editado trabaja en detalle cada una de estas "oleadas" (Feld \& Salvi, 20I9). La primera "oleada" (I984 y I985) comprende el llamado "show del horror", las tareas de la CONADEP y el juicio a los excomandantes. En un contexto de sentidos en pugna y significados todavía no estabilizados sobre las desapariciones, las declaraciones de prepetradores permitieron entender las cambiantes fronteras de lo decible y escuchable (Feld, 20I9), así como el
} 
entender de qué modo las declaraciones se vinculaban con determinadas condiciones de posibilidad y escucha. Más que enfocarnos en los dichos de los perpetradores de manera aislada, nos interesó comprender los momentos de emergencia como escenarios sobredeterminados (de determinación múltiple) en los que esas voces se articularon con las formaciones discursivas, las memorias sociales y los marcos de sentido socialmente disponibles en un terreno de disputas. De modo que fue necesario atender a las fases de activación o desaceleración en las luchas por las memorias sobre el terrorismo de Estado, pero especialmente a los vaivenes de la acción judicial. Los ciclos de persecución penal y de impunidad fueron un factor sustantivo pues nos permitieron indagar en la relación entre el valor de la información que dieron los represores y las mediaciones colectivas e institucionales para construir una verdad social sobre el terrorismo de Estado. Específicamente, pudimos analizar los mecanismos disponibles en cada coyuntura para autorizar y legitimar estas voces militares, entendiendo que han sido múltiples, complejos y diversos. En este aspecto, el estudio de los llamados Juicios por la Verdad, cuyo carácter no punitivo echó luz sobre el contexto de impunidad, ya que mostró cómo se reprodujo el silenciamiento en las filas de las FF. AA., aun a varias décadas de terminada la dictadura (Andriotti Romanin, 20I9).

En suma, el estudio diacrónico y sincrónico en oleadas hizo foco en la dinámica de las transformaciones de sentido como un proceso multivariado y articulado de elementos tales como espacio, tiempo, escucha, saberes, escenarios, mediaciones institucionales y políticas, entre otros. Esto definitivamente ayudó a complejizar los abordajes de tipo descriptivo, que se han ocupado de clasificar tipos de guiones, escenarios, contextos, actores (Payne, 2008). Si bien esas aproximaciones taxonómicas fueron un punto de partida

posicionamiento de los militares ante el debate más amplio sobre la "responsabilidad" de los crímenes (Galante, 20I9). La segunda "oleada" (I995-I998), iniciada con las declaraciones de Scilingo, se desplegó en un contexto de impunidad (Feld, 2009; Verbitsky, I995). En ella, una serie de declaraciones de represores con contenidos disímiles se interpretó a través de la noción de "arrepentimiento" aunque esos represores muchas veces reivindicaron sus crímenes (Feld, 20I6; Messina, 20I9). La tercera "oleada" se produjo en el marco de los "Juicios por la Verdad" a partir de I999. Dado su carácter no punitivo, los represores fueron convocados en calidad de testigos bajo "juramento a decir verdad". Algunos rangos bajos brindaron información relevante y, en ciertos casos, hablaron de las tareas que desempeñaban en los centros clandestinos (Andriotti Romanin, 20I9). Una cuarta "oleada" se produjo a partir de 2005, con los juicios por crímenes de lesa humanidad. La presencia amplia de represores en las audiencias orales en condición de imputados constituyó un hecho inédito. Si bien como acusados podían abstenerse de declarar, muchos emitieron desde arengas políticas y acusaciones hacia las víctimas hasta informaciones relevantes sobre el aparato represivo (Salvi, 20I9b; Garaño, 20I9). 
para nuestro estudio, consideramos que la perspectiva analítica aquí desarrollada resulta superadora y ayuda a comprender más cabalmente los procesos sociales, políticos y memoriales en los que las declaraciones de perpetradores tienen lugar.

\section{A modo de conclusión}

Retomando el seminario Pensar relacionalmente, este articulo buscó volver de manera reflexiva sobre aquello que Bourdieu (2015: 313) ha definido como "la operación más crucial de la investigación y aun así la más completamente ignorada", esto es, la construcción del objeto. De este modo pudimos enlazar, a partir de la experiencia de investigación, lo empírico, lo teórico y lo metodológico para poner de manifiesto los recortes, las perspectivas, las articulaciones que hicieron posible delinear un objeto, como ya dijimos, sociológicamente relacional e históricamente multitemporal.

A partir de una mirada integral sobre los resultados alcanzados en la investigación, este artículo provee claves conceptuales y metodológicas, así como herramientas analíticas y heurísticas para estudiar la palabra pública de los perpetradores. Ante la pregnancia de individuos que toman la palabra en primera persona y el peso de los dichos de sujetos que estuvieron como partícipes en la escena del crimen, este trabajo presentó diversos elementos analíticos para que esta condición fenomenológica del objeto de observación no se vuelva un obstáculo para el análisis del objeto de estudio. En este sentido, buscamos brindar elementos para, primero, pensar la figura del perpetrador como un fenómeno relacional y, segundo, desesencializar su palabra atendiendo a sus condiciones históricas de producción y escucha. Para ello, resultó fundamental complejizar los relatos en primera persona como parte de una trama, una red de procesos que funcionan articuladamente. Nos interesó mostrar el carácter contingente de estos modos de construcción y valoración de la palabra de los perpetradores, para atender a las maneras en que es socialmente producida, demandada y escuchada en diversos contextos. Asimismo, el estudio sincrónico y diacrónico de la palabra de los represores nos permitió reconstruir la red de procesos que articulan la emisión, circulación, interpretación y recepción de estos dichos. En síntesis, consideramos que el planteo teórico-metodológico aquí desarrollado da pistas que pueden ser enriquecidas a partir del análisis de otros casos, en diversas situaciones y contextos históricos, pues se propone como una caja de herramientas abierta a nuevas y más complejas interpretaciones. 


\section{Bibliografía}

Andriotti Romanin, Enrique. 20I9. De militar a torturador. Las declaraciones de Julián "el Laucha” Corres en el Juicio por la Verdad de Bahía Blanca. En Feld, Claudia \& Salvi, Valentina (dirs.) Las voces de la represión. Declaraciones de perpetradores de la dictadura argentina. Buenos Aires: Miño y Dávila, I95-2I9.

Arfuch, Leonor. I995. Confesiones, conmemoraciones. Punto de vista 52: I-I6.

Austin, John. I996. Cómo hacer cosas con palabras. Barcelona: Paidós.

Bourdieu, Pierre. 2005. Pensar relacionalmente. En Bourdieu, Pierre \& Wacquant, Loïc. Una invitación a la sociología reflexiva. Buenos Aires: Siglo XXI, 3I3-326.

Canelo, Paula. 20r9. La H es muda, pero habla. El relato público de Albano Harguindeguy sobre la represión y los desaparecidos (I976-20I2). En Feld, Claudia \& Salvi, Valentina (dirs.) Las voces de la represión. Declaraciones de perpetradores de la dictadura argentina. Buenos Aires: Miño y Dávila, 59-82.

Da Silva Catela, Ludmila. 200I. No habrá flores en la tumba del pasado. La experiencia de reconstrucción del mundo de los familiares de los desaparecidos. La Plata: Ediciones al Margen.

Diz, María Luisa. 2020. Declaraciones públicas y artes escénicas: la construcción de personajes y narrativas de apropiadores y apropiadoras en teatro $\mathrm{x}$ la identidad (2000-200I). Kamchatka Revista de Análisis Cultural I5: 27I-292. doi: https:// doi.org/IO.7203/KAM.I5.I5494

Feld, Claudia. 200I. La construcción del arrepentimiento: los ex represores en televisión. Entrepasados 20: 35-54.

Feld, Claudia. 2009. Entre la visibilidad y la justicia: los testimonios televisivos de represores en la Argentina. Encuentros Uruguayos 2: 42-57. http://www. encuru.fhuce.edu.uy/images/revistas/REVISTA-ENCUENTROS-URUGUAYOS-2009.pdf [Acceso I2/03/202I]

Feld, Claudia. 20I9a. En busca de la imagen del represor. Las entrevistas al ex cabo Vilariño en la revista La Semana (I984). En Feld, Claudia \& Salvi, Valentina (dirs.) Las voces de la represión. Declaraciones de perpetradores de la dictadura argentina. Buenos Aires: Miño y Dávila, ı05-129.

Feld, Claudia. 2orgb. Del “debate” imposible a la negación de los hechos: las declaraciones de Etchecolatz en I997. En Feld, Claudia \& Salvi, Valentina (dirs.) Las voces de la represión. Declaraciones de perpetradores de la dictadura argentina. Buenos Aires: Miño y Dávila, I73-I94.

Feld, Claudia \& Franco, Marina. 20I5. Democracia y derechos humanos en I984, ¿hora cero?. En Feld, Claudia \& Franco, Marina (dirs.) Democracia, hora cero. Actores, politicas y debates en los inicios de la posdictadura. Buenos Aires: Fondo de Cultura Económica, 356-400.

Feld, Claudia \& Salvi, Valentina. 20I6. Presentación. Cuando los perpetradores hablan. Dilemas y tensiones en torno a una voz controvertida. Rúbrica Contemporánea 9: I-Io https://revistes.uab.cat/rubrica/article/viewFile/v5-n9-feld-salvi /II6-pdf-es [Acceso I2/04/202I] 
Feld, Claudia \& Salvi, Valentina. 20I9a. (dirs.) Las voces de la represión. Declaraciones de perpetradores de la dictadura argentina. Buenos Aires: Miño y Dávila.

Feld, Claudia \& Salvi, Valentina. 2orgb. Declaraciones públicas de represores de la dictadura argentina: temporalidades, escenarios y debates. En Feld, Claudia \& Salvi, Valentina (dirs.) Las voces de la represión. Declaraciones de perpetradores de la dictadura argentina. Buenos Aires: Miño y Dávila, II-34.

Feld, Claudia \& Salvi, Valentina. 2020a. La palabra de los perpetradores y el problema de la verdad en Argentina: Entre el silencio y la justicia. Revista Eletrônica da ANPHLAC I9: I3-44. doi: https://doi.org/10.46752/anphlac.29.2020.3905

Feld, Claudia \& Salvi, Valentina. 202ob. La construcción social de la figura del perpetrador: procesos sociales, luchas políticas, producciones culturales. Kamchatka Revista de Análisis Cultural I5: 5-I5. doi: https://doi.org/I0.7203/KAM.I5.I768I

Ferrer, Anacleto \& Sánchez Biosca, Vicente. 20I9. (dir.) El infierno de los perpetradores. Imágenes, relatos, conceptos. Valencia: Edicions Bellaterra.

Galante, Diego. 20i9. Culpables de nada y responsables de todo: los ex comandantes y el Juicio a las Juntas. En Feld, Claudia \& Salvi, Valentina (dirs.) Las voces de la represión. Declaraciones de perpetradores de la dictadura argentina. Buenos Aires: Miño y Dávila, I3I-I49.

Garaño, Santiago. 20I9. Un testigo anómalo. Un análisis del proceso de construcción como testigo de un ex gendarme enviado al Operativo Independencia. En Feld, Claudia \& Salvi, Valentina (dirs.) Las voces de la represión. Declaraciones de perpetradores de la dictadura argentina. Buenos Aires: Miño y Dávila, 223-240.

Giesen, Bernard. 200I. Sobre héroes, víctimas y perpetradores. La construcción pública del mal y del bien común. Revista Puentes 2: I6-23.

Hilb, Claudia. 20I4. Justicia, reconciliación y perdón. ¿Cómo fundar una comunidad después del crimen? En Claudia Hilb, Philippe-Josep Salazar \& Lucas Martin (orgs.) Lesa humanidad. Argentina y Sudáfrica: reflexiones después del Mal. Buenos Aires: Katz, 53-74.

Jelin, Elizabeth. 20I7. La lucha por el pasado: Cómo construimos la memoria social. Buenos Aires: Siglo XXI.

Mariani, Ana. 20I8. La Cuca. María Graciela Antón, la única mujer sentenciada a cadena perpetua por delitos de lesa humanidad. Buenos Aires: Aguilar.

Martin, Lucas. 20I7. El otro (o la transformación de Scilingo). En Martin, Lucas (org.) Un pasado criminal. Sudáfrica y Argentina: argumentos y documentos para el debate. Buenos Aires: Katz, 69-Io9.

Messina, Luciana. 20I9. Reflexiones en torno a la figura del torturador: el caso del “Turco Julián”. En Feld, Claudia \& Salvi, Valentina (dirs.) Las voces de la represión. Declaraciones de perpetradores de la dictadura argentina. Buenos Aires: Miño y Dávila, I53-I72.

Muzzopappa, Eva. 20I9. El hilo de Mayorga. Coherencia moral para la lógica represiva (I972-2006). En Feld, Claudia \& Salvi, Valentina (dirs.) Las voces de la represión. Declaraciones de perpetradores de la dictadura argentina. Buenos Aires: Miño y Dávila, 37-57. 
Oberti, Alejandra \& Pittaluga, Roberto. 20ı6. Apuntes para una discusión sobre la memoria y la política de los años 60/70 a partir de algunas intervenciones recientes. Sociohistórica 38: I-22. http://www.memoria.fahce.unlp.edu.ar/ library?a=d\&c=arti\&d=Jpr7650 [Acceso 6/05/2021]

Payne, Leigh. 2008. Unsettling Accounts. Neither Truth nor Reconciliation in Confessions of State Violence. Durham/Londres: Duke University Press.

Ranalletti, Mario. 20ı8. Violencia extrema y delito en el marco de la campaña de represión clandestina en Argentina (I976-I983). Amnis. Revue de civilisation contemporaine Europes/Amériques I7 : I-I2. https://journals.openedition.org/ amnis/3499 [Acceso 6/05/2021]

Ricoeur, Paul. I999. La lectura del tiempo pasado: memoria y olvido. Madrid: Ediciones UAM.

Salazar, Philippe-Joseph. 20I7. El “perpetrador”, o el crimen fundador. En Martin, Lucas (org.) Un pasado criminal. Sudáfrica y Argentina: argumentos y documentos para el debate. Buenos Aires: Katz, 5I-67.

Salvi, Valentina. 20г2. De vencedores a víctimas. Memorias militares sobre el pasado reciente en la Argentina. Buenos Aires: Biblos.

Salvi, Valentina. 20I5. Guerra, subversivos y muertos. Un estudio sobre las declaraciones de militares en el primer año de democracia. En Feld, Claudia \& Franco, Marina (dirs.) Democracia, hora cero. Actores, políticas y debates en los inicios de la posdictadura. Buenos Aires: Fondo de Cultura Económica, I53-I93.

Salvi, Valentina. 20I6. Los represores como objeto de estudio. Obstáculos, problemas y dificultades para su investigación en Argentina. Cuadernos del IDES 32: 22-4I. https://static.ides.org.ar/archivo/www/2012/03/Cuadernos -del-IDES-32-2016.pdf [Acceso 6/05/202I]

Salvi, Valentina. 2orga. "Para que la sociedad no se diera cuenta". Las declaraciones de Videla sobre los desaparecidos. En Feld, Claudia \& Salvi, Valentina (dirs.) Las voces de la represión. Declaraciones de perpetradores de la dictadura argentina. Buenos Aires: Miño y Dávila, 83-IO2.

Salvi, Valentina. 2orgb. Los dichos de Eduardo “Tucu” Costanzo y la construcción de la verdad. En Feld, Claudia \& Salvi, Valentina (dirs.) Las voces de la represión. Declaraciones de perpetradores de la dictadura argentina. Buenos Aires: Miño y Dávila, 24I-26I.

Salvi, Valentina. 2020. Trayectoria, capital e ideología. Las declaraciones de los perpetradores en los juicios por crímenes de lesa humanidad en Argentina. Kamchatka Revista de Análisis Cultural I5: I93-215. doi: https://doi.org/10.7203/ KAM.I5.I570I

Scott, Joan. 200I. Experiencia. La ventana I7: 42-73. http://revistalaventana.cucsh. udg.mx/index.php/LV/article/view/55I/574 [Acceso 6/05/202I]

Verbitsky, Horacio. I995. El Vuelo. Buenos Aires: Planeta.

Verzero, Lorena. 2020. Construcción performativa de la autoridad: entramado de sentidos en apariciones públicas, imágenes y representaciones de Videla. Kamchatka Revista de Análisis Cultural I5: 2I7-24I. doi: https://doi.org/10.7203/ KAM.I5. 15748 